\title{
Cost-utility analysis of genotype-guided
} antiplatelet therapy in patients with moderate-tohigh risk acute coronary syndrome and planned percutaneous coronary intervention

\author{
Vardhaman PATEL, Fang-Ju LIN, Olaitan OJO, Sapna RAO, Shengsheng YU, Lin ZHAN, Daniel R. TOUCHETTE.
} Received (first version): 28-Mar-2014

Accepted: 15-Aug-2014

\begin{abstract}
*
Background: Prasugrel is recommended over clopidogrel in poor/intermediate CYP2C19 metabolizers with acute coronary syndrome (ACS) and planned percutaneous coronary intervention $(\mathrm{PCl})$, reducing the risk of ischemic events. CYP2C19 genetic testing can guide antiplatelet therapy in ACS patients.

Objective: The purpose of this study was to evaluate the cost-utility of genotype-guided treatment, compared with prasugrel or generic clopidogrel treatment without genotyping, from the US healthcare provider's perspective. Methods: A decision model was developed to project lifetime economic and humanistic burden associated with clinical outcomes (myocardial infarction [MI], stroke and major bleeding) for the three strategies in patients with ACS. Probabilities, costs and age-adjusted quality of life were identified through systematic literature review. Incremental cost-utility ratios (ICURs) were calculated for the treatment strategies, with quality-adjusted life years (QALYs) as the primary effectiveness outcome. Relative risk of developing myocardial infarction and stroke between patients with and without variant CYP2C19 when receiving clopidogrel were estimated to be 1.34 and 3.66 , respectively. One-way and probabilistic sensitivity analyses were performed.

Results: Clopidogrel cost USD19,147 and provided 10.03 QALYs versus prasugrel (USD21,425, 10.04 QALYs) and genotype-guided therapy (USD19,231, 10.05 QALYs). The ICUR of genotype-guided therapy compared with clopidogrel was USD4,200. Genotype-guided therapy provided more QALYs at lower costs compared with prasugrel. Results were sensitive to the cost of clopidogrel and relative risk of myocardial infarction and stroke between CYP2C19 variant vs. non-variant. Net monetary benefit curves showed that genotype-guided therapy had at least $70 \%$ likelihood of being the most cost-effective
\end{abstract}

"Vardhaman PATEL. MSc. Department of Pharmacy Systems, Outcomes and Policy, University of Illinois at Chicago. Chicago, IL, (United States)

Fang-Ju LIN. PhD. Pharmerit North America LLC Bethesda, MD (United States).

Olaitan OJO. PharmD, MBA, BCPS. Pharmacoeconomic Center, Department of Defense. Fort Sam Houston, TX (United States)

Sapna RAO. MSc. Department of Epidemiology, University of North Carolina, Chapel Hill, NC (United States).

Shengsheng YU. PhD. Global Health Outcomes, Merck Sharp \& Dohme Corp. Whitehouse Station, NJ (United States)

Lin ZHAN. MSc. Eisai Inc. Woodcliff Lake, NJ (United States).

Daniel R. TOUCHETTE. PharmD, MA. Departments of Pharmacy Practice and Pharmacy Systems, Outcomes and Policy, University of Illinois at Chicago. Chicago, IL (United States).drtouche@uic.edu alternative at a willingness-to-pay of USD100,000/QALY. In comparison with clopidogrel, prasugrel therapy was more cost-effective with $<21 \%$ certainty at willingness-topay of $>$ USD170,000/QALY

Conclusions: Our modeling analyses suggest that genotype-guided therapy is a cost-effective strategy in patients with acute coronary syndrome undergoing planned percutaneous coronary intervention.

Keywords: Clopidogrel; Prasugrel; Acute Coronary Syndrome; Polymorphism, Genetic; Genetic Testing Costs and Cost Analysis; United States

\section{INTRODUCTION}

Coronary heart disease is the most common cause of death in the US, responsible for 1 in every 6 deaths in $2010 .^{1}$ Every year, approximately 620,000 Americans experience a new incident of myocardial infraction (MI) or coronary heart disease death, and an estimated 295,000 experience a recurrent event. ${ }^{1}$ The treatment of these patients can place a substantial financial burden on the US healthcare system. The estimated annual direct and indirect cost for coronary heart disease is approximately USD204.4 billion of which a large portion is due to acute coronary syndrome. ${ }^{1}$ Hence, analyses to identify cost effective treatment options are imperative.

Clopidogrel, in combination with aspirin, is widely accepted as the current standard of treatment and has demonstrated efficacy in preventing atherothrombotic events after the occurrence of acute coronary syndrome, including unstable angina, non-ST-elevation myocardial infarction, and ST-elevation myocardial infarction. ${ }^{2}$ Clopidogrel is a prodrug that requires metabolic activation catalyzed by several cytochrome P450 (CYP) isoenzymes. ${ }^{3}$ Results of studies that evaluated the association between genetic polymorphism in the CYP2C19 enzyme (at least one of the reduced function allele) and risk of adverse events are inconsistent. ${ }^{4}$ Three retrospective observational studies have found an increase in the risk of stent thrombosis among clopidogrel-treated patients with genetic polymorphism (OR range 1.59:5.60). ${ }^{5-7}$ However, other observational studies and substudies of randomized clinical trials have failed to find similar results. ${ }^{8,9}$ Given these inconsistent results, it is prudent to draw conclusions via a meta-analysis of 
all published studies. A meta-analysis by Bauer et al. found statistically significant association between genetic polymorphism and stent thrombosis (OR $1.7795 \% \mathrm{Cl} 1.31: 2.40)$ but not composite end point (OR $1.1195 \% \mathrm{Cl}$ 0.89:1.39). ${ }^{10}$ However, a more recent meta-analysis that includes more studies has shown that genetic polymorphism increases the risk of composite end point (OR $1.5095 \% \mathrm{Cl} 1.21: 1.87$ ), myocardial infarction (OR $1.6295 \% \mathrm{Cl} 1.35: 1.95$ ) and ischemic stroke (OR $2.1495 \% \mathrm{Cl} 1.36: 3.38){ }^{4}$ The most common reduced-function allele is the CYP2C $19 * 2 .{ }^{11}$ Approximately $50 \%$ of Chinese, $34 \%$ of African Americans, $25 \%$ of Whites, and $19 \%$ of Mexican Americans carry at least 1 copy of the reduced function CYP2C $19 * 2$ allele. ${ }^{12}$ Additionally, about $14 \%$ of Chinese, $4 \%$ of African Americans, and $2 \%$ of Whites are considered poor metabolizers (two variant alleles). ${ }^{12,13}$

Given the evidence of reduced clopidogrel effectiveness in patients with reduced-function CYP2C19 variants, the US Food and Drug Administration (FDA) issued a black box warning and advised clinicians to consider genetic testing for CYP2C19 as an aid in determining clinical treatment strategy. ${ }^{13}$ The Current Clinical Pharmacogenetics Implementation Consortium (CPIC) guidelines recommend the use of an alternate therapy, such as prasugrel, for CYP2C19 poor metabolizers if no contraindication is present. ${ }^{14}$ Prasugrel, a newer thienopyridine, is not affected by the CYP2C19 polymorphism. 15

Genotype-guided therapy offers a promising approach in individualizing therapeutic options, in which prasugrel is indicated for patients with CYP2C19 reduced-function variants and clopidogrel is reserved for patients with no genetic variation. Two studies evaluated the cost-effectiveness of genotype-guided antiplatelet therapy from a payer's perspective. ${ }^{16,17}$ Reese et al. found that genotypeguided antiplatelet therapy strategy was dominant (less costly and more effective) compared with treatment with prasugrel for all patients regardless of genotype, and was cost-effective when compared with generic clopidogrel (hypothetical cost of USD1/day). However, the study used number of events avoided (thrombotic plus bleeding) as the unit of effectiveness. ${ }^{17}$ As thrombotic and bleeding events have a different impact on patient quality of life, the evaluation of this combined endpoint in a cost-effectiveness ratio may be misleading. Lala et al. found genotype-guided therapy to be the dominant strategy for base-case analysis at 15 months. ${ }^{16}$ However, their study ignored long-term costs associated with outcomes.

The aim of our study was to evaluate the cost-utility of genotype-guided antiplatelet therapy, compared with clopidogrel and prasugrel therapy without genotyping in acute coronary syndrome patients with planned percutaneous coronary intervention $(\mathrm{PCl})$, from a healthcare provider's perspective.

\section{METHODS}

\section{Decision model}

A 15-month decision-analysis model was developed using TreeAge Pro 2014 (TreeAge Software Inc., Williamstown, MA) to account for clinical outcomes in patients with moderate-to-high risk acute coronary syndrome and planned $\mathrm{PCl}^{18,19}$ Both costs and quality-adjusted life years (QALYs) associated with clinical outcomes were evaluated and extrapolated to the patients' life expectancy (Figure 1). The model was designed to compare prasugrel plus aspirin, clopidogrel plus aspirin, and genotype-guided therapy for patients receiving bare-metal stent or drug-eluting stent. In the genotype-guided therapy arm, patients with CYP2C19 reduced-function polymorphism (at least one of the following reduced-function alleles: * $1 \mathrm{~A}$, ${ }^{*} 2 \mathrm{~A},{ }^{*} 3,{ }^{*} 4,{ }^{*} 5 \mathrm{~A},{ }^{*} 6,{ }^{*} 7,{ }^{*} 8,{ }^{*} 9,{ }^{*} 10,{ }^{*} 12,{ }^{*} 13,{ }^{*} 14$, *17) were given prasugrel plus aspirin whereas patients without the polymorphism were given clopidogrel plus aspirin.

Outcomes modeled were divided into two periods, immediate hospitalization (first 30 days) and longterm ( $2^{\text {nd }}$ to $15^{\text {th }}$ month), based on the time frames that most clinical trials reported results. Clinical outcomes modeled included myocardial infarction (nonprocedural and procedural), urgent target vessel revascularization, major bleeding, stroke, death due to bleeding, and death due to other cardiovascular causes. Death was assumed to occur only due to myocardial infarction, ischemic stroke, major bleeding, or other cardiovascular causes like dysrhythmia, cardiogenic shock, hypertension, pulmonary embolism or atherosclerotic vascular disease. Major bleeding not related to coronary artery bypass graft was defined as intracranial, retroperitoneal bleeding or bleeding requiring transfusion of 4 units or more (when decrease in hemoglobin is $5 \mathrm{~g} / \mathrm{dL}$ or more). ${ }^{20}$ Incremental cost-utility ratios (ICUR) were calculated as the ratio of the differences in costs and QALYs of two treatment strategies. The ICUR for a more costly treatment was interpreted as the additional cost (relative to the less costly treatment) that would be incurred for a unit gain in QALY. A willingness-to-pay threshold of USD100,000 per additional QALY was used to identify the most costeffective treatment strategy. In the base case analysis, point estimates obtained via literature review were used to calculate the costs and QALYs associated with each treatment. In addition, the impact of uncertainty associated with point estimates on the ICUR and net monetary benefit was evaluated by sensitivity analyses.

\section{Probabilities}

As described above, the model was divided into initial (30-day) and long-term outcomes. In the absence of reported outcomes at 30 days, we estimated that fifty-nine percent of outcomes (myocardial infarction, stroke, cardiovascular death, major bleeding) occurred during the first 30 days from reported Kaplan-Meier curves. ${ }^{19}$ 


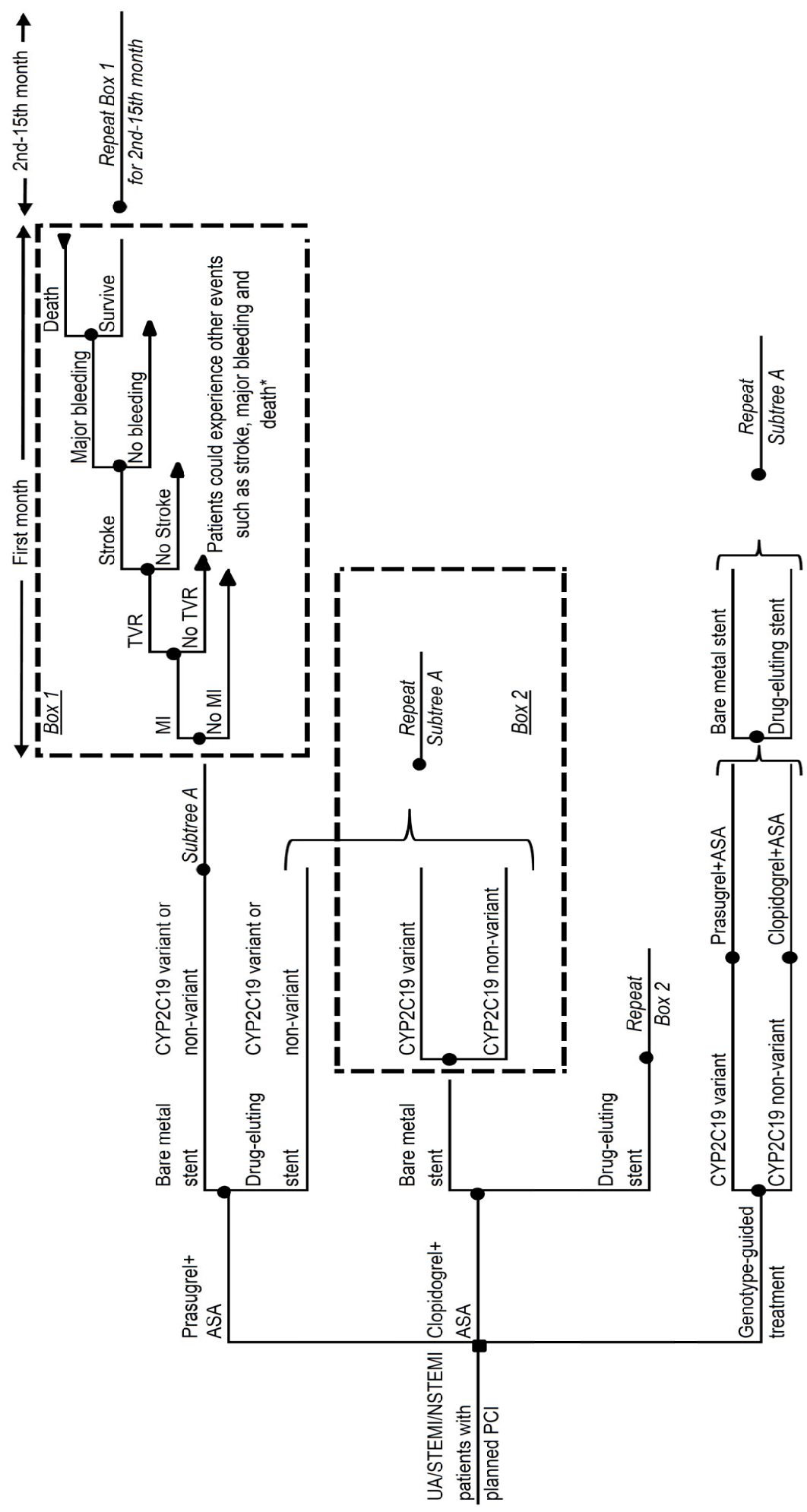

Figure 1. Antiplatelet treatment strategies for ACS patients with planned PCI. Clinical outcomes were modeled for two periods postindex $\mathrm{PCl}$ i.e. first 30 days, $2^{\text {nd }}-15^{\text {th }}$ month. Only patients who developed myocardial infarction post-index $\mathrm{PCl}$ underwent target vessel revascularization.

$\mathrm{UA}=$ unstable angina; NSTEMI= non-ST elevation myocardial infarction; STEMI= ST elevation myocardial infarction; $\mathrm{PCl}=$ percutaneous coronary intervention; $\mathrm{MI}=$ myocardial infarction; $\mathrm{ASA}=$ aspirin; $\mathrm{TVR}=$ target vessel revascularization; $\mathrm{CYP} 2 \mathrm{C} 19=$ cytochrome P450 2C19.

* The subtree consisting of stroke, major bleeding and death was repeated for patients without myocardial infarction. Similarly, the subtree consisting of major bleeding and death was repeated for patients without stroke. Death was included as a possible terminal outcome only if the patient had experienced any of the event(s). 
Patel V, Lin FJ, Ojo O, Rao S, Yu S, Zhan L, Touchette DR. Cost-utility analysis of genotype-guided antiplatelet

therapy in patients with moderate-to-high risk acute coronary syndrome and planned percutaneous coronary

intervention. Pharmacy Practice 2014 Jul-Sep;12(3):438.

\begin{tabular}{|c|c|c|c|}
\hline Outcome & $\begin{array}{c}\text { Cost in USD } \\
\text { (standard error) }\end{array}$ & Reference & Notes \\
\hline $\begin{array}{l}\text { Myocardial infarction } \\
\text { Hospitalization } \\
\text { a } \\
\text { Post-discharge cost for } 1^{\text {st }} \\
\text { Cost per year after } 1^{\text {st }} \text { year }\end{array}$ & $\begin{array}{r}23,524(3,827) \\
19,933(3,243) \\
2,575(419)\end{array}$ & $\begin{array}{l}45,46 \\
45,46\end{array}$ & $\begin{array}{l}\text { Cost of } \mathrm{Ml} \text { excludes } \mathrm{PCl} \text {. Cost of hospitalization had been } \\
\text { multiplied by a factor of } 1.089 \text { to account for recurrent events. } \\
1.089 \text { is the ratio of number of } \mathrm{Ml} \text { events to the number of } \\
\text { patients. }\end{array}$ \\
\hline $\begin{array}{r}\text { CABG } \\
\text { BMS as type of } \mathrm{PCI} \\
\text { DES as type of } \mathrm{PCI}\end{array}$ & $\begin{array}{r}30,332(354) \\
5,921(3,375) \\
9,770(5,569)\end{array}$ & $\begin{array}{c}43 \\
44,47 \\
44,47\end{array}$ & $\begin{array}{l}\text { Weighted costs of TVR were calculated for patient subgroups } \\
\text { i.e. DES and BMS type of stent during index } \mathrm{PCI} \text { procedure. } \\
\text { Weight applied to the cost of } \mathrm{CABG}=0.12 \text {; weight applied to } \\
\text { the cost of BMS/DES }=0.88 .^{18} \text { Weights represent proportion of } \\
\text { patients undergoing CABG vs. PCI. } \\
\text { Weighted cost of TVR for BMS subgroup=USD8,866 }(2,980) \text {. } \\
\text { Weighted cost of TVR for DES subgroup=USD12,258 }(4,854) \text {. }\end{array}$ \\
\hline $\begin{array}{r}\text { Stroke } \begin{array}{l}\text { Hospitalization } \\
{ }^{\text {a }}\end{array} \\
{\text { Post-discharge cost for } 1^{\text {st }}}_{\text {year }} \\
\text { Cost per year after } 1^{\text {st }} \text { year }\end{array}$ & $\begin{array}{r}9,650(2,837) \\
40,932(12,034) \\
19,238(5,656) \\
\end{array}$ & $\begin{array}{c}46,48 \\
46,48,49 \\
46,49 \\
\end{array}$ & $\begin{array}{l}\text { Estimate obtained by subtracting hospitalization cost from the } \\
\text { first year total cost of USD } 50,582.49\end{array}$ \\
\hline $\begin{array}{r}\text { Major bleeding } \\
\text { Hospitalization } \\
\text { Post-discharge cost for } 1^{\text {st }} \\
\text { year }\end{array}$ & $\begin{array}{r}8,978(988) \\
10,722(1,180)\end{array}$ & $\begin{array}{l}20,48,50-52 \\
20,48,49\end{array}$ & $\begin{array}{l}\text { Hospitalization cost of ICH was subtracted from the first year } \\
\text { total cost of } \mathrm{ICH}=\mathrm{USD} 72,926-\mathrm{USD} 28,120=\mathrm{USD} 44,806 \text {. } \\
\text { Bleeding cost }=0.2393 \times \text { USD } 44,806=\mathrm{USD} 10,722 \text {. } \\
\text { Bleeding cost }=0.2393 \times \text { USD9,630 }\end{array}$ \\
\hline \multicolumn{4}{|c|}{$\begin{array}{l}\text { MI= myocardial infarction; BMS = bare-metal stent; DES= drug-eluting stent; CABG = coronary artery bypass graft; PCI= percutaneous coronary } \\
\text { intervention; ICH = intracranial hemorrhage. } \\
{ }^{\dagger} \text { All cost inputs were varied between } \pm 50 \% \text { for one-way sensitivity analyses. Cost estimates have been expressed as } 2011 \text { USD. } \\
{ }^{a} \text { Emergency room visit cost of USD854 }(816) \text { was added to post-discharge incidences of MI, stroke and major bleeding. }{ }^{30}, 53 \text { Based on a length of } \\
\text { stay of } 3 \text { days, }{ }^{36} \text { one third of } \mathrm{MI},{ }^{19} \text { stroke and major bleeding incidences during first } 30 \text { days were post-discharge. } \\
{ }^{b} \text { Weighted by the probability of retroperitoneal bleeding }(0.2237), I C H(0.2393) \text {, and transfusion }(0.5369) \text {. Weighted cost includes emergency room } \\
\text { visit. } \\
{ }^{c} \text { We assumed that only ICH incured post-discharge cost. }\end{array}$} \\
\hline
\end{tabular}

\section{Cost of care}

Costs have been expressed as 2011 US dollars (Table 2). Costs were inflated, using data from medical care component of the Consumer Price Index, when necessary. ${ }^{26}$ Costs incurred after $1^{\text {st }}$ year were discounted at a $5 \%$ rate. Costs related to the index $\mathrm{PCl}$ procedure, pharmacotherapy supporting $\mathrm{PCl}$, inpatient physician visits and inpatient laboratory tests were not included as these costs were incurred for all patients in the three comparison groups. Including these costs would not affect the incremental cost-utility ratio (ICUR). Outpatient physician visits and nursing home costs post-discharge were included. Fifty percent (discount) of the lowest average wholesale price was used as the cost for drugs. Average wholesale price was USD4.5 per $10 \mathrm{mg}$ prasugrel tablet, USD0.19 per $75 \mathrm{mg}$ generic clopidogrel tablet and USD0.002 per $81 \mathrm{mg}$ aspirin. ${ }^{27}$ The cost of genetic testing was estimated to be USD300 based on institutional data. ${ }^{28}$ Antiplatelet drug related costs were incurred only during the 15 months follow-up period in the model. Discharge day physician visit was estimated to cost USD105 while outpatient physician visit was estimated to cost USD $110 .{ }^{29}$ We assumed that there would be 1 outpatient visit during the first 30 days and 5 visits from $2^{\text {nd }}$ to $15^{\text {th }}$ month if no clinical events occurred. Monthly average cost of nursing home stay and outpatient laboratory testing were estimated to be USD9 and USD125, respectively. ${ }^{30}$ Rehabilitation costs were not included for patients who developed a fatal event during the first 30 days. Only inpatient costs were considered for retroperitoneal bleeding and transfusion while both inpatient and long-term costs were considered for $\mathrm{Ml}$, stroke, and intracranial hemorrhage.

\section{Life expectancy and quality of life}

The Declining Exponential Approximation of Life Expectancy (DEALE) was used to estimate the life expectancy. ${ }^{31}$ Age- and complication-adjusted life expectancy was estimated to be 20 years (Table 3 ). EQ-5D score for 61 years old individuals in the U.S. population was reported to be $0.85 .^{32}$ Age-adjusted quality of life (QOL) scores for patients who developed myocardial infarction and intracranial hemorrhage were identified from studies that used the EQ-5D instrument. ${ }^{33,34} \mathrm{QOL}$ for stroke patients was obtained from a meta-analysis study that combined scores obtained by direct and indirect methods. ${ }^{35}$ Disutilities associated with long-term complications like thrombotic stroke, myocardial infarction and intracranial hemorrhage were calculated as the difference between 0.85 and QOL of patients who developed complications. A conservative QOL of zero was assumed for the duration of inpatient stay (average of 3 days) contributed by the $\mathrm{PCl}$ procedure. ${ }^{36}$ Disutilities associated with myocardial infarction, stroke and intracranial hemorrhage were estimated to be 0.15 , 0.33 and 0.23 , respectively. ${ }^{18,33-35}$ QALYs beyond the first year were discounted at a $5 \%$ rate. 


\begin{tabular}{|c|c|c|c|}
\hline Variable & Value & Reference & Notes \\
\hline Compound mortality rate $\left(\mu_{c}\right)$ & 0.05276 & $19,31,54$ & $\begin{array}{l}\text { 10-year survival rates for acute } \mathrm{MI} \text { and UA patients were } \\
57.5 \% \text { and } 60.2 \% \text {, respectively. Weighted } 10 \text {-year } \\
\text { survival rate was estimated to be } 59.49 \% \text { using } \\
\text { information on the proportion of STEMI, NSTEMI and UA } \\
\text { patients from the TRITON-TIMI } 38 \text { trial. For ACS patients } \\
\text { with mean age } 61.2 \text { years, } \mu_{C}=-1 / \mathrm{t} \times \ln (\mathrm{S})=0.05276 ; \mathrm{t}=10 \\
\text { years; } \mathrm{S}=59.49 \% \text {. }\end{array}$ \\
\hline Age specific population mortality rate $\left(\mu_{\text {pop }}\right)$ & 0.04629 & $31,54,55$ & $\begin{array}{l}\text { For an average age of } 61.2 \text { years, life expectancy from } \\
\text { the vital statistics life table was } 21.6 \text { years. } \\
\mu_{\text {pop }}=1 / 21.6=0.04629 \text {. }\end{array}$ \\
\hline Disease-specific morality rate $\left(\mu_{d}\right)$ & 0.00647 & - & $\mu_{d}=\mu_{C}-\mu_{p o p}=0.00647$ \\
\hline Baseline mortality rate $\left(\mu_{\mathrm{ASR}}\right)$ & 0.04464 & $19,31,54$ & $\begin{array}{l}\text { The mean age of patients in the TRITON-TIMI } 38 \text { clinical } \\
\text { trial was } 60.9 \text { years. Age-, sex-, and race-adjusted life } \\
\text { expectancy from the vital statistics life table was } 22.4 \\
\text { years. } \mu_{\text {ASR }}=1 / 22.4=0.04464 \text {. Adjusted life expectancy } \\
=1 /\left[\mu_{\mathrm{d}}+\mu_{\mathrm{ASR}}\right]=20 \text { years. }\end{array}$ \\
\hline \multicolumn{4}{|c|}{$\begin{array}{l}\text { MI= myocardial infarction; NSTEMI = non-ST elevation myocardial infarction; STEMI= ST elevation myocardial infarction; UA= } \\
\text { unstable angina. } \\
{ }^{\dagger} \text { Age-and complication-adjusted life expectancy method as recommended by Beck et al. }{ }^{31}\end{array}$} \\
\hline
\end{tabular}

\section{Sensitivity analyses}

One-way sensitivity analyses were performed on all variables to assess the robustness of results to the uncertainty associated with probabilities, disutilities and costs individually. The purpose of one-way sensitivity analyses was to assess the impact of each variable on the expected cost and QALYs of each treatment. The results were considered to be robust to the uncertainty associated with a variable when the incremental cost-utility ratio (ICUR) did not cross the USD100,000/QALY willingness-to-pay threshold. We have provided the values of variables at which the ICUR crosses this threshold or preference for a therapy changes. Upper and lower limits of $95 \%$ confidence intervals were used as ranges for the one-way sensitivity analyses for probabilities, relative risks and disutilities. The prevalence of polymorphism (at least one CYP2C19 reduced-function allele) and cost of genetic test were varied over a broad range $(15 \%$ to $75 \%$ and USD150 to USD900, respectively) due to the potential differences between races. Studies reported costs of complications that were substantially different from each other for a variety of reasons, including differences in patient mix, assessed charges and not costs, duration of followup, geographical variation, sample size, and single vs. multiple institution data. Therefore, we used a range of $50 \%$ of the original cost in one-way sensitivity analyses. The daily maintenance cost of clopidogrel was varied between USD0.19 and USD14.89 based on the lowest and highest average wholesale price in the market. ${ }^{27}$ The discount rate was varied between $2 \%$ and $5 \%$.

As previously mentioned, clopidogrel is a prodrug that is metabolized to its active compound by CYP2C19. When clopidogrel metabolism is reduced, there is a higher risk of thrombosis. Although statistically significant findings were observed in the composite endpoint of death from cardiovascular causes, myocardial infarction, or stroke, Mega et al. found consistent, but not statistically significant differences in the individual endpoints of myocardial infarction or stroke. ${ }^{3}$ In addition, there were differences between patients in this genetic substudy and the overall trial. The proportion of patients with STEMI, Caucasians, and females was higher while the proportion of patients with hypercholesterolemia was lower in the genetic substudy compared with the overall trial $(P<0.05)$. Therefore, using one-way sensitivity analyses, we varied the risk of having myocardial infarction or ischemic stroke in those with CYP2C19 polymorphism relative to those without to assess the impact of this important factor on choice of therapy.

Probabilistic sensitivity analyses (multiway) was conducted to assess the overall model variability. The purpose of multiway sensitivity analysis was to assess the impact of all variables on the expected costs and QALYs of treatments simultaneously. All relevant probabilities and utilities were assigned beta distribution while the costs of outcomes were assigned gamma distribution for $2^{\text {nd }}$ order Monte Carlo simulation (10,000 iterations). Results have been presented as net monetary benefit curves. Net monetary benefit curves indicate the probability that a strategy is most cost-effective at various willingness-to-pay thresholds (USD0 USD500,000/QALY).

\section{RESULTS}

\section{Base-case analysis}

Clopidogrel (USD19,147, 10.03 QALYs) therapy was the least costly and least effective treatment compared to prasugrel (USD21,425, 10.04 QALYs) and genotype-guided therapy (USD19,231, 10.05

\begin{tabular}{|l|c|c|c|c|c|c|c|c|}
\hline Table 4. Base case results \\
\hline Strategy & $\begin{array}{c}\text { Life } \\
\text { years }\end{array}$ & $\begin{array}{c}\text { Cost } \\
\text { (USD) }\end{array}$ & QALYs & $\begin{array}{c}\Delta \text { Cost } \\
\text { (USD) }\end{array}$ & $\Delta$ QALYs & $\begin{array}{c}\text { ICUR } \\
\text { (USD) }\end{array}$ & $\begin{array}{c}\text { MB at } \\
\text { USD50,000/ } \\
\text { QALY }\end{array}$ & $\begin{array}{c}\text { MB at } \\
\text { USD100,000 } \\
\text { /QALY }\end{array}$ \\
\hline Clopidogrel & 19.1204 & 19,147 & 10.03 & - & - & - & $\$ 482,353$ & $\$ 983,853$ \\
\hline Genotype-guided therapy & 19.1326 & 19,231 & 10.05 & 84 & 0.02 & 4,200 & $\$ 483,269$ & $\$ 985,769$ \\
\hline Prasugrel & 19.1305 & 21,425 & 10.04 & 2,194 & -0.01 & Dominated & $\$ 480,575$ & $\$ 982,575$ \\
\hline
\end{tabular}


Patel V, Lin FJ, Ojo O, Rao S, Yu S, Zhan L, Touchette DR. Cost-utility analysis of genotype-guided antiplatelet

therapy in patients with moderate-to-high risk acute coronary syndrome and planned percutaneous coronary

intervention. Pharmacy Practice 2014 Jul-Sep;12(3):438.

RR for stroke (CYP2C19 variant vs. non-variant) [Range: 0.53-18]

Cost of daily maintenance dose (clopidogrel) [Range: \$0.19-\$14.89]

Cost of genetic test [Range: \$150-\$900]

Cost of MI [Range: $50 \%-150 \%$ ]

Probability of stroke (clopidogrel) [Range: 77\%-125\%]

Probability of MI (clopidogrel) [Range: 92\%-108\%]

Probability of stroke (prasugrel) [Range: 77\%-126\%]

Prevalence of polymorphism [Range: 50\%-250\%]

Probability of MI (prasugrel) [Range: 91\%-109\%]

Discount rate [Range: $2 \%-5 \%$ ]

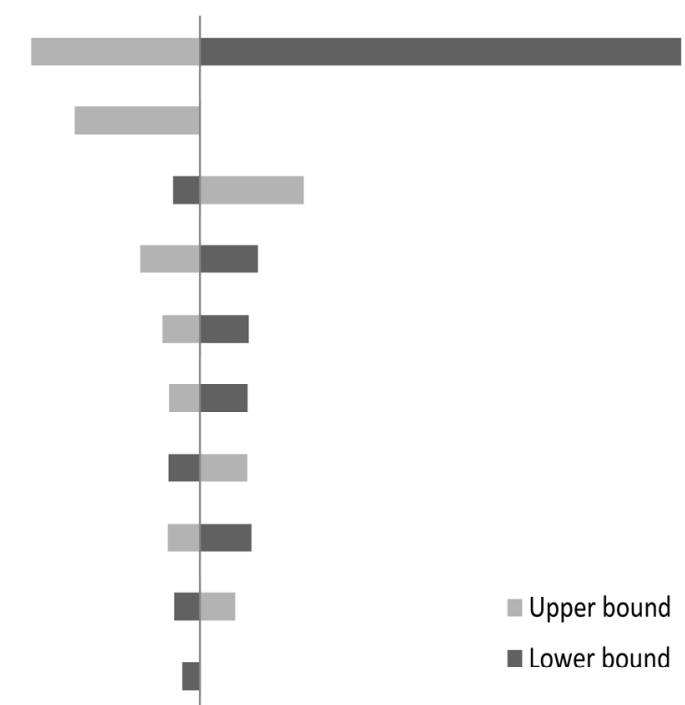

$-\$ 50$

Incremental cost (US \$000) per QALY

$\$ 100$

$\$ 150$

Figure 2. Tornado diagram showing one-way sensitivity analyses for cost-utility of genotype-guided therapy compared to clopidogrel therapy.

Vertical axis represents the base case incremental cost-utility ratio (ICUR) while horizontal axis represents the change in ICUR relative to base case for variables subjected to one-way sensitivity analyses.

Ranges presented above indicate the lower and upper limits for each variable, expressed as a percentage of base-case value $\mathrm{RR}=$ relative risk; CYP2C19= cytochrome P450 2C19; MI= myocardial infarction; $\mathrm{QALY}=$ quality-adjusted life year.

QALYs) (Table 4). There was a modest gain in QALYs from the use of genotype-guided therapy. Compared to clopidogrel therapy, genotype-guided therapy increased QALYs by an additional 0.02 QALYs at an increased cost of USD84, resulting in an ICUR of USD4,200 per QALY gained. Prasugrel therapy was more costly and less effective than genotype-guided therapy. The ICUR of prasugrel therapy, when compared with clopidogrel therapy, was USD227,800 per QALY gained with an increase in both QALYs and cost by an additional 0.01 and USD2,278, respectively.

\section{Sensitivity analyses}

One-way sensitivity analyses showed that the costutility of genotype-guided therapy (vs. clopidogrel therapy) was sensitive to the uncertainty associated with the relative risk of developing $\mathrm{Ml} /$ stroke between patients with and without CYP2C19 polymorphism. However, it was robust to the uncertainty associated with prevalence of CYP2C19 polymorphism, discount rate, all disutilities, probability of myocardial infarction/stroke, and cost of genetic testing, myocardial infarction/stroke/bleeding/target vessel revascularization, and clopidogrel (Figure 2). The ICUR for genotype-guided therapy decreased from USD18,254/QALY to -USD4,615/QALY as the prevalence of polymorphism increased from $15 \%$ to $75 \%$. The genotype-guided therapy dominated clopidogrel therapy when prevalence was $\geq 42 \%$. Threshold analysis revealed that genotype-guided therapy became less attractive compared to clopidogrel therapy when prevalence of polymorphism decreased to $\leq 6.6 \%$ and $\leq 3.6 \%$ as ICUR increased to >USD50,000/QALY and $>$ USD100,000/QALY, respectively. The ICUR for genotype-guided therapy remained $<$ USD50,000/QALY as cost of genetic testing increased from USD150 to USD900. As the risk of developing myocardial infarction between patients with and without CYP2C19 polymorphism decreased (i.e. became more similar), genotypeguided therapy became less attractive. Genotypeguided therapy was cost-effective when the relative risk was between 1.13-1.40 as ICUR was $\leq 50,000 / Q A L Y$ and dominated clopidogrel at all relative risks $\geq 1.40$. The ICUR for genotype-guided therapy compared to clopidogrel was $>$ USD50,000/QALY and >USD100,000/QALY when the relative risk of developing myocardial infarction (CYP2C19 variant vs. non-variant) was $\leq 1.10$ and $<1.02$, respectively. Similarly, when the risk of ischemic stroke was varied, relative risk of $<1.65$ and $<0.77$ resulted in ICURs of $>$ USD50,000/QALY and >USD100,000/QALY, respectively. The genotype-guided therapy dominated clopidogrel therapy when relative risk of ischemic stroke was 24.07. Compared to prasugrel therapy, the costutility of genotype-guided therapy was robust to the uncertainty associated with disutilities, costs and probabilities of outcomes. However, the ICUR for genotype-guided therapy increased to $>$ USD50,000/QALY when the cost of clopidogrel was more than USD9.88 per day.

When compared with clopidogrel, the cost-utility of prasugrel therapy was robust to the uncertainty associated with discount rate, all disutilities, and cost of myocardial infarction. Prasugrel therapy was cost-effective only when the prevalence of CYP2C19 polymorphism and cost of clopidogrel was $\geq 45 \%$ and USD3.99 per day, respectively. Prasugrel therapy became attractive (vs. clopidogrel therapy) when the relative risk (CYP2C19 variant 


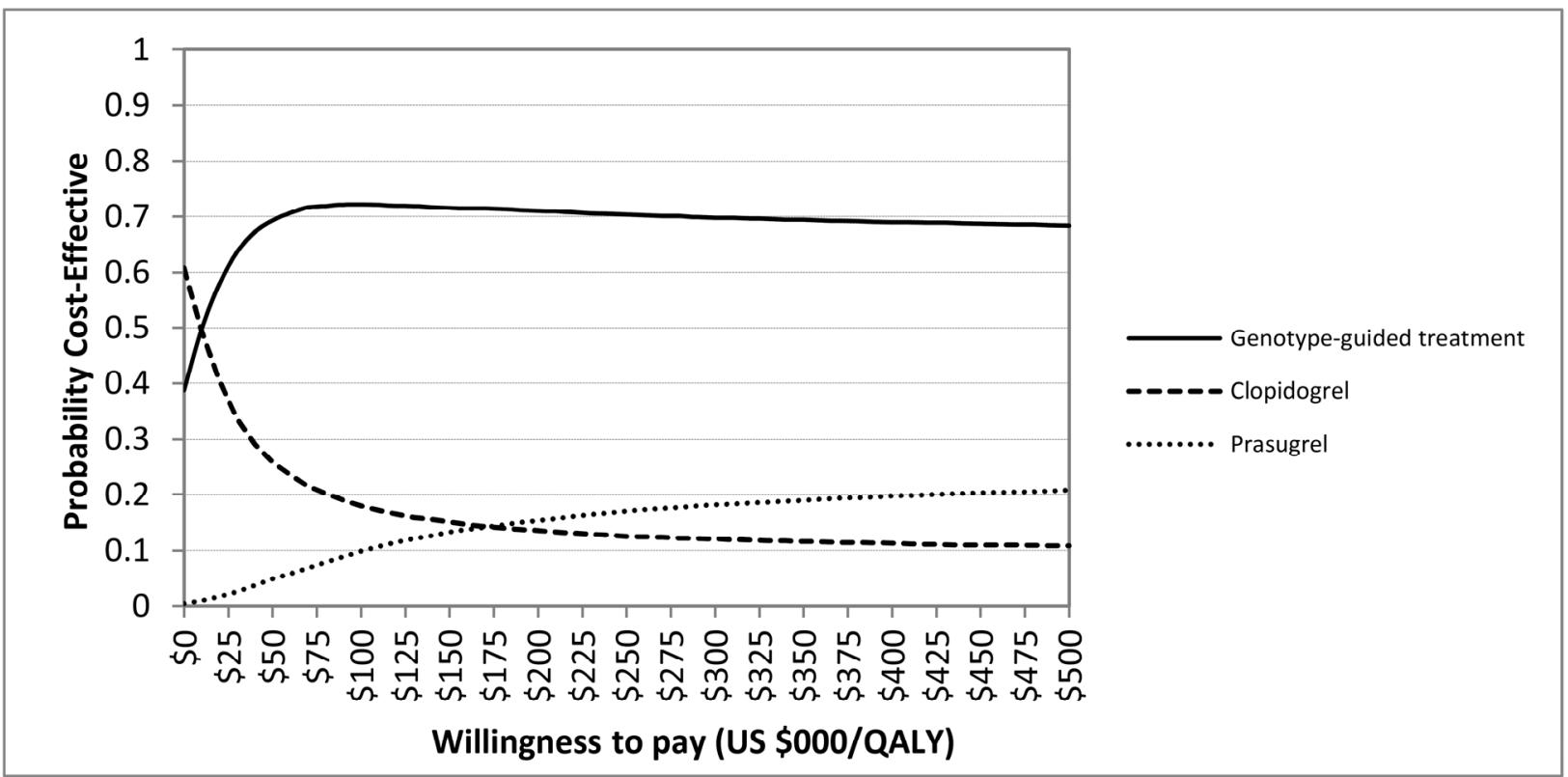

Figure 3. Net monetary benefit curves showing probability of a strategy being the most cost-effective alternative over a range of willingness-to-pay values. $\mathrm{QALY}=$ quality-adjusted life year.

vs. non-variant) of developing myocardial infarction was $\geq 1.67$ as ICUR dropped to <USD100,000/QALY; clopidogrel therapy was dominant or ICUR for prasugrel therapy was $>$ USD100,000/QALY when the relative risk of developing $\mathrm{MI}$ was $<1.67$. Prasugrel therapy was dominant or ICUR was <USD100,000/QALY when the relative risk (CYP2C19 variant vs. non-variant) of developing stroke was $\geq 6.75$.

Results from probabilistic sensitivity analyses have been presented as net monetary benefit curves in Figure 3. Considerable variation in ICURs was observed in the ICUR scatter plot for all three comparisons due to small differences in QALYs between the three strategies. Regardless of the willingness-to-pay threshold, genotype-guided therapy had a higher likelihood of being the costeffective strategy compared to prasugrel therapy. Genotype-guided therapy had $>70 \%$ likelihood of being the most cost-effective strategy for willingness-to-pay $\geq U S D 60,000 / Q A L Y$. For all willingness-to-pay thresholds $\geq$ USD10,000/QALY, genotype-guided therapy had a higher probability $(\geq 0.5)$ of being cost-effective compared to clopidogrel therapy. In the scenario where genetic testing is not available, clopidogrel therapy is the treatment of choice (vs. prasugrel therapy) due to the higher likelihood of it being cost-effective when willingness-to-pay $\leq$ USD170,000/QALY. The choice of therapy would change at a very high willingnessto-pay (>USD170,000/QALY) as the probability of clopidogrel being the most cost-effective alternative is less than that of prasugrel.

\section{DISCUSSION}

For the base case analysis, our results showed that genotype-guided therapy was cost-effective when compared with clopidogrel, with an ICUR below USD50,000 per QALY. In general, differences in QALYs between the three treatment strategies were minimal. We found that genotype-guided antiplatelet therapy strategy was less costly and more effective than prasugrel therapy. When genetic testing is not an option for clinicians, clopidogrel is likely preferred, as prasugrel is not likely an efficient option with an ICUR of USD227,800 per QALY gained. Multiway sensitivity analysis gave us confidence that genotype-guided antiplatelet therapy would be the preferred option for a wide range of willingness-to-pay per additional QALY values in spite of the uncertainties in point estimates.

To our knowledge, three published studies have looked at the value of genotype-guided antiplatelet therapy, although only one assessed the costeffectiveness of alternate strategies. ${ }^{16,17,37}$ Both Reese et al. and Lala et al. evaluated the costeffectiveness of genotype-guided antiplatelet therapy from a payer's perspective. ${ }^{16,17}$ Reese et al. found this strategy to be dominant (less costly and more effective) compared with treatment with prasugrel (ICER -USD11,710 per event avoided) or clopidogrel (ICER -USD6,760). When the generic cost of clopidogrel at an estimated USD1/pill was considered, genotyping was still more cost effective than prasugrel (ICER -USD27,160) but less cost savings were realized when compared with clopidogrel (ICER USD2,300 per event avoided) for all patients, regardless of genotype. The interpretation of these results is limited because of the use of a composite outcome (number of events avoided) combining thrombotic and bleeding events. As the average severity and impact on quality of life of thrombotic and bleeding events is considerably different, the composite outcome does not accurately reflect an appropriate weight for each event. Quality of life or utility measures (i.e. QALYs) are a much more appropriate methodology for pooling together both thrombotic and bleeding outcomes. Lala et al. found genotype-guided therapy to be dominant to both prasugrel and clopidogrel at both 15 months and 10 years. 
Although similar to our findings, our model found genotype-guided therapy dominated prasugrel, but not clopidogrel therapy. Our study differs from Lala et al. in that Lala et al. did not take into account long-term costs associated with myocardial infarction, stroke and bleeding, major bleeding was defined differently with higher rates of bleeding, and patients with CYP2C19 carriers were given a higher bleeding rate than were non-carriers. ${ }^{16}$ Difference in bleeding between carriers and non-carriers administered clopidogrel was found to be similar and not significantly different (hazard ratio $=1.01$; $p=0.98) .^{3}$ It is not clear why Lala et al. used a major bleeding rate that was higher in carriers than noncarriers, therefore biasing the analysis towards prasugrel and genotype-guided therapy. Genotype screening of acute coronary syndrome patients undergoing $\mathrm{PCl}$ was also evaluated in a risk benefit assessment study by Guzauskas et al. ${ }^{37}$ The results showed that the genotype-guided strategy had greater probability of greater net benefit as compared to prasugrel $(+0.03$ QALY; $95 \% \mathrm{Cl}$ $0.13: 0.24)$ and clopidogrel (+0.05 QALY; $95 \% \mathrm{Cl}$ $0.02: 0.11)$. Although this study did not intend to evaluate the economic implications on patient outcomes, the findings concur with our study, highlighting the value of genetic testing for guiding antiplatelet therapy.

With regard to the comparison of empirical prasugrel and clopidogrel treatment, our findings are not consistent with the previous studies, which suggested that prasugrel is cost-effective in patients with acute coronary syndrome undergoing $\mathrm{PCl}{ }^{18,38}$ Mahoney et al. evaluated the cost-effectiveness of prasugrel versus clopidogrel from the perspective of the US healthcare system, using actual TRITONTIMI 38 trial patient-level data subset from eight countries, rather than the overall TRITON-TIMI 38 trial patients. ${ }^{18}$ Prasugrel was the dominant strategy in the initial 30 days of treatment, as long as the difference in drug price was less than USD7.67/day. For treatment over the full study duration (median follow-up of 14.7 months), prasugrel (USD5.45/day) had higher medication costs than generic clopidogrel (USD1.00/day) with a difference in acquisition costs of USD996 per person. Prasugrel also increased QALY (difference $=0.0955$ ) with a corresponding ICUR of USD10,429 per QALY gained. The study findings were mainly driven by the difference of rehospitalization costs of USD517 per person (favoring prasugrel), which was derived from a study subset of 8 countries participating the TIMI-38 trial, and the risk reduction by prasugrel (absolute risk reduction of $3.6 \%$ ) in $\mathrm{PCl}$ during rehospitalization. ${ }^{18}$ While the absolute risk reduction for target vessel revascularization (includes PCI \& coronary artery bypass graft) for all patients in the TRITON-TIMI 38 trial has been reported elsewhere as $1.2 \%,{ }^{19}$ Mahoney et al. could have overestimated the benefits of prasugrel. Furthermore, this study applied the same costs to all survivors beyond 15 months, but not taking into account differences in long-term costs of treating ischemic stroke or intracranial hemorrhage beyond the first 15 months.

Another cost-effectiveness study was conducted by Mauskopf et al. from a managed care organization perspective, simply with life expectancy gains as the unit of effectiveness in the analysis. ${ }^{38}$ In this analysis, the cost per life year gained, with the use of prasugrel, ranged from USD6,642 to USD13,906, based on the lower cost of generic clopidogrel. As with Mahoney et al., ${ }^{18}$ this study did not adequately consider differences in long term cost of care for survivors of ischemic stroke or intracranial hemorrhage. Neither of these studies considered the cost-effectiveness of genotype guided therapy.

We found our study results, however, to be sensitive to the relative risk of developing $\mathrm{Ml} /$ stroke in clopidogrel-treated patients with and without CYP2C19 polymorphism. Our results indicate that genotype-guided therapy would be a cost-effective approach if the relative risk of developing myocardial infarction (between CYP2C19 polymorphism carrier and non-carrier) is higher than 1.02, with the threshold of ICUR set at USD100,000/QALY. Similarly, genotype-guided management would be cost-effective if the relative risk of developing stroke is higher than 0.77 . In a recent meta-analysis by Holmes et al., the overall relative risks of developing myocardial infarction and stroke in CYP2C19 polymorphism carriers are $1.37(95 \% \mathrm{Cl} \quad 1.13: 1.65)$ and $1.98 \quad(95 \% \mathrm{Cl}$ $0.77: 5.09)$, respectively. ${ }^{39}$ The relative risk of myocardial infarction associated with CYP2C19 polymorphism in most study populations are above the threshold of 1.02, suggesting that our study results remain robust irrespective of the relative risk for myocardial infarction across different populations. On the other hand, the relative risk of stroke associated with CYP2C19 greatly varies across the limited number of studies with a wide confidence interval that contains the null value, indicating that our findings may be sensitive to the relative risk for stroke in the corresponding study population.

Although clopidogrel was shown to be more costeffective than prasugrel, its use may be hampered by potential drug-drug interaction (e.g., with protonpump inhibitors) and delayed onset of action. ${ }^{40}$ On the other hand, prasugrel is not without its own limitations, including higher bleeding risk and FDA restrictions on its use. The subgroup analysis of TIMI-38 clinical trial suggests that prasugrel should be contraindicated in patients with a history of stroke or transient ischemic attack and that it appears to be less effective in patients $\geq 75$ years old and those $<60 \mathrm{~kg}$. $^{19,41}$ Additionally, prasugrel is only approved for patients with acute coronary syndrome undergoing planned $\mathrm{PCl}$ while clopidogrel is approved for recent stroke, myocardial infarction (treated with $\mathrm{PCl}$ or medically) and peripheral artery disease. ${ }^{13,23}$ Hence, the choice of medication should be based on physician and patient preferences and characteristics as well as economic considerations.

Our analysis is not without limitations. First, the reliance on TRITON-TIMI 38 study and its substudies as the source of clinical data may limit the generalizability of study results. Our model accounts for events occurring within 15 months of index $\mathrm{PCl}$ because no data is available to project the outcomes beyond the study follow-up period. In 
addition, given that the vast majority (92\%) of the study participants in the TRITON-TIMI 38 trial were Caucasians, there is a concern that the results may not adequately represent the broader population since the prevalence of CYP2C19 polymorphism varies across racial groups. However, one-way sensitivity analysis (clopidogrel vs. genotype-guided therapy) revealed that results are robust to variation in the prevalence of variant genotypes across racial groups. The ICUR for genotype-guided therapy decreased from USD18,254/QALY to USD4,615/QALY as the prevalence of polymorphism increased from $15 \%$ to $75 \%$. Compared with clopidogrel, prasugrel therapy was the most cost-effective strategy only when the prevalence of CYP2C19 polymorphism was $\geq 45 \%$. We also assumed that the genotyped subgroup of TIMI-38 trial patients who were allocated prasugre ${ }^{15}$ and clopidogrel $^{3}$ are representative of the overall study cohort, in terms of response to medication and treatment outcomes.

\section{CONCLUSIONS}

Our economic analysis demonstrated that, despite initiation costs, genotype-guided antiplatelet therapy is cost-effective when compared with clopidogrel and dominant when compared with prasugrel. When genetic testing is not available, clopidogrel is a more cost-effective strategy when compared with prasugrel, but the choice should be based on patient characteristics as well as economic considerations.

\section{CONFLICT OF INTEREST}

This research received no specific grant from any funding agency in the public, commercial, or not-forprofit sectors. The study abstract was presented as a poster at the American College of Clinical Pharmacy Annual Meeting, October 21-24, 2012, Hollywood, Florida, USA.
ANÁLISIS COSTE-UTILIDAD DEL

TRATAMIENTO ANTIPLAQUETARIO GUIADO POR GENOTIPADO EN PACIENTES CON RIESGO ALTO-A-MODERADO DE SÍNDROME CORONARIO AGUDO Y INTERVENCIÓN CORONARIA PERCUTÁNEA PLANEADA

\section{RESUMEN}

Antecedentes: Presugrel se recomienda sobre clopidogrel en metabolizadores pobres del CYP2C19 con síndrome coronario agudo (ACS) e intervención percutánea coronaria planeada (PCI), reduciéndose el riesgo de eventos isquémicos. El testado genético de CYP2C19 puede guiar la terapéutica antiplaquetaria en pacientes con ACS.

Objetivo: Evaluar el coste-utilidad del tratamiento guiado por genotipo, comparado con el prasugrel o el clopidogrel genérico sin genotipado, desde la perspectiva del proveedor sanitario en Estados Unidos.

Métodos: Se desarrolló un modelo de decisión para proyectar el coste económico y humanístico durante la vida asociado con los resultados clínicos (infarto de miocardio [MI], accidente cerebrovascular (ACV), y hemorragia mayor) para las tres estrategias en pacientes con ACS. Se identificaron mediante revisión sistemática de la literatura las probabilidades, costes y calidad de vida ajustada a la edad. Se calcularon los ratios de costeutilidad incrementales (ICUR) para las estrategias de tratamiento, con los años de vida ajustados según la calidad (QALY) como resultado primario de efectividad. Se estimó que el riesgo relativo de desarrollar MI y ACV entre los pacientes con y sin variante CYP2C19 cuando recibían clopidogrel era de 1,34 and 3,66, respectivamente. Se realizó un análisis de sensibilidad probabilístico de una cola.

Resultados: El clopidogrel costó USD19.147 y proporcionó 10,03 QALY contra el prasugrel (USD21.425, 10,04 QALYs). El ICUR del tratamiento guiado por genotipado comparado con el clopidogrel fue de USD4.200. El tratamiento guiado por genotipado proporcionó más QALY a menor coste comparado con el prasugrel. Los resultados eran sensibles al coste de clopidogrel y al riesgo relativo de MI y ACV entre los variantes y no variantes CYP2C19. Las curvas de beneficios netos monetarios mostraban que el tratamiento guiado por genotipado tenía al menos un $70 \%$ de probabilidad de ser la alternativa más coste-efectiva con una voluntad de pagar de USD100.000/QALY. En comparación con el clopidogrel, el tratamiento con prasugrel fue más coste-efectivo con un $21 \%$ de certeza a una voluntad de pagar > USD170.000/QALY.

Conclusiones: Nuestros análisis de modelos sugieren que el tratamiento guiado por genotipado es una estrategia coste-efectiva en pacientes con síndrome coronario agudo que sufren una intervención percutánea coronaria planeada.

Palabras clave: Clopidogrel; Prasugrel; Síndrome Coronario Agudo; Polimorfismo Genético; Pruebas Genéticas; Costos y Análisis de Costo; Estados Unidos

1. Go AS, Mozaffarian D, Roger VL, Benjamin EJ, Berry JD, Blaha MJ, Dai S, Ford ES, Fox CS, Franco S, Fullerton HJ, Gillespie C, Hailpern SM, Heit JA, Howard VJ, Huffman MD, Judd SE, Kissela BM, Kittner SJ, Lackland DT, Lichtman $\mathrm{JH}$, Lisabeth LD, Mackey RH, Magid DJ, Marcus GM, Marelli A, Matchar DB, McGuire DK, Mohler ER, 3rd, Moy CS, Mussolino ME, Neumar RW, Nichol G, Pandey DK, Paynter NP, Reeves MJ, Sorlie PD, Stein J, Towfighi A, Turan TN, Virani SS, Wong ND, Woo D, Turner MB. Heart disease and stroke statistics--2014 update: a report from the american heart association. Circulation. 2014;129(3):e28-e292. doi: 10.1161/01.cir.0000441139.02102.80

2. Vandvik PO, Lincoff AM, Gore JM, Gutterman DD, Sonnenberg FA, Alonso-Coello P, AkI EA, Lansberg MG, Guyatt GH, Spencer FA. Primary and secondary prevention of cardiovascular disease: Antithrombotic Therapy and Prevention of 
Patel V, Lin FJ, Ojo O, Rao S, Yu S, Zhan L, Touchette DR. Cost-utility analysis of genotype-guided antiplatelet therapy in patients with moderate-to-high risk acute coronary syndrome and planned percutaneous coronary intervention. Pharmacy Practice 2014 Jul-Sep;12(3):438.

Thrombosis, 9th ed: American College of Chest Physicians Evidence-Based Clinical Practice Guidelines. Chest. 2012;141(2 Suppl):e637S-e668S. doi: 141/2_suppl/e637S

3. Mega JL, Close SL, Wiviott SD, Shen L, Hockett RD, Brandt JT, Walker JR, Antman EM, Macias W, Braunwald E, Sabatine MS. Cytochrome p-450 polymorphisms and response to clopidogrel. N Engl J Med. 2009;360(4):354-362. doi: NEJMoa0809171

4. Mao L, Jian C, Changzhi L, Dan H, Suihua H, Wenyi T, Wei W. Cytochrome CYP2C19 polymorphism and risk of adverse clinical events in clopidogrel-treated patients: a meta-analysis based on 23,035 subjects. Arch Cardiovasc Dis. 2013;106(10):517-527. doi: 10.1016/j.acvd.2013.06.055

5. Collet JP, Hulot JS, Pena A, Villard E, Esteve JB, Silvain J, Payot L, Brugier D, Cayla G, Beygui F, Bensimon G, FunckBrentano C, Montalescot G. Cytochrome P450 2C19 polymorphism in young patients treated with clopidogrel after myocardial infarction: a cohort study. Lancet. 2009;373(9660):309-317. doi: 10.1016/s0140-6736(08)61845-0

6. Giusti B, Gori AM, Marcucci R, Saracini C, Sestini I, Paniccia R, Buonamici P, Antoniucci D, Abbate R, Gensini GF Relation of cytochrome P450 2C19 loss-of-function polymorphism to occurrence of drug-eluting coronary stent thrombosis. Am J Cardiol. 2009;103(6):806-811. doi: 10.1016/j.amjcard.2008.11.048

7. Harmsze AM, van Werkum JW, Ten Berg JM, Zwart B, Bouman HJ, Breet NJ, van 't Hof AW, Ruven HJ, Hackeng CM, Klungel $\mathrm{OH}$, de Boer A, Deneer VH. CYP2C19*2 and CYP2C9*3 alleles are associated with stent thrombosis: a casecontrol study. Eur Heart J. 2010;31(24):3046-3053. doi: 10.1093/eurheartj/ehq321

8. Simon T, Verstuyft C, Mary-Krause M, Quteineh L, Drouet E, Meneveau N, Steg PG, Ferrieres J, Danchin N, Becquemont L. Genetic determinants of response to clopidogrel and cardiovascular events. N Engl J Med. 2009;360(4):363-375. doi: 10.1056/NEJMoa0808227

9. Wallentin L, James S, Storey RF, Armstrong M, Barratt BJ, Horrow J, Husted S, Katus H, Steg PG, Shah SH, Becker RC. Effect of CYP2C19 and ABCB1 single nucleotide polymorphisms on outcomes of treatment with ticagrelor versus clopidogrel for acute coronary syndromes: a genetic substudy of the PLATO trial. Lancet. 2010;376(9749):1320-1328. doi: 10.1016/s0140-6736(10)61274-3

10. Bauer T, Bouman HJ, van Werkum JW, Ford NF, ten Berg JM, Taubert D. Impact of CYP2C19 variant genotypes on clinical efficacy of antiplatelet treatment with clopidogrel: systematic review and meta-analysis. BMJ (Clinical research ed). 2011;343:d4588. doi: 10.1136/bmj.d4588

11. Scott SA, Sangkuhl K, Gardner EE, Stein CM, Hulot JS, Johnson JA, Roden DM, Klein TE, Shuldiner AR. Clinical Pharmacogenetics Implementation Consortium guidelines for cytochrome P450-2C19 (CYP2C19) genotype and clopidogrel therapy. Clin Pharmacol Ther. 2011;90(2):328-332. doi: clpt2011132

12. Holmes DR, Jr., Dehmer GJ, Kaul S, Leifer D, O'Gara PT, Stein CM. ACCF/AHA clopidogrel clinical alert: approaches to the FDA "boxed warning": a report of the American College of Cardiology Foundation Task Force on clinical expert consensus documents and the American Heart Association endorsed by the Society for Cardiovascular Angiography and Interventions and the Society of Thoracic Surgeons. J Am Coll Cardiol. 2010;56(4):321-341. doi: S07351097(10)01997-2

13. Plavix (clopidogrel bisulfate) [package insert]. Bridgewater, NJ: Bristol-Myers Squibb/Sanofi Pharmaceuticals Partnership; 2011.

14. Scott SA, Sangkuhl K, Stein CM, Hulot JS, Mega JL, Roden DM, Klein TE, Sabatine MS, Johnson JA, Shuldiner AR. Clinical Pharmacogenetics Implementation Consortium guidelines for CYP2C19 genotype and clopidogrel therapy: 2013 update. Clin Pharmacol Ther. 2013;94(3):317-323. doi: 10.1038/clpt.2013.105

15. Mega JL, Close SL, Wiviott SD, Shen L, Hockett RD, Brandt JT, Walker JR, Antman EM, Macias WL, Braunwald E, Sabatine MS. Cytochrome P450 genetic polymorphisms and the response to prasugrel: relationship to pharmacokinetic, pharmacodynamic, and clinical outcomes. Circulation. 2009;119(19):2553-2560. doi: CIRCULATIONAHA.109.851949

16. Lala A, Berger JS, Sharma G, Hochman JS, Scott Braithwaite R, Ladapo JA. Genetic testing in patients with acute coronary syndrome undergoing percutaneous coronary intervention: a cost-effectiveness analysis. J Thromb Haemost. 2013;11(1):81-91.

17. Reese ES, Daniel Mullins C, Beitelshees AL, Onukwugha E. Cost-effectiveness of cytochrome P450 2C19 genotype screening for selection of antiplatelet therapy with clopidogrel or prasugrel. Pharmacotherapy. 2012;32(4):323-332.

18. Mahoney EM, Wang K, Arnold SV, Proskorovsky I, Wiviott S, Antman E, Braunwald E, Cohen DJ. Cost-effectiveness of prasugrel versus clopidogrel in patients with acute coronary syndromes and planned percutaneous coronary intervention: results from the trial to assess improvement in therapeutic outcomes by optimizing platelet inhibition with Prasugrel-Thrombolysis in Myocardial Infarction TRITON-TIMI 38. Circulation. 2010;121(1):71-79. doi: CIRCULATIONAHA.109.900704

19. Wiviott SD, Braunwald E, McCabe CH, Montalescot G, Ruzyllo W, Gottlieb S, Neumann FJ, Ardissino D, De Servi S, Murphy SA, Riesmeyer J, Weerakkody G, Gibson CM, Antman EM. Prasugrel versus clopidogrel in patients with acute coronary syndromes. N Engl J Med. 2007;357(20):2001-2015. doi: NEJMoa0706482

20. Pinto DS, Stone GW, Shi C, Dunn ES, Reynolds MR, York M, Walczak J, Berezin RH, Mehran R, McLaurin BT, Cox DA, Ohman EM, Lincoff AM, Cohen DJ. Economic evaluation of bivalirudin with or without glycoprotein Ilb/Illa inhibition versus heparin with routine glycoprotein IIb/IIla inhibition for early invasive management of acute coronary syndromes. $\mathrm{J}$ Am Coll Cardiol. 2008;52(22):1758-1768. doi: S0735-1097(08)02876-3

21. Wiviott SD, Braunwald E, McCabe CH, Horvath I, Keltai M, Herrman JP, Van de Werf F, Downey WE, Scirica BM, Murphy SA, Antman EM. Intensive oral antiplatelet therapy for reduction of ischaemic events including stent thrombosis in patients with acute coronary syndromes treated with percutaneous coronary intervention and stenting in the TRITONTIMI 38 trial: a subanalysis of a randomised trial. Lancet. 2008;371(9621):1353-1363. doi: S0140-6736(08)60422-5

22. Unger EF. Prasugrel for reduction of cardiovascular events in patients with acute coronary syndrome (ACS) Silver Spring, Maryland: U.S. Food and Drug Administration; 2009 [updated Feb 3 2009;]. Available from: http://www.fda.gov/ohrms/dockets/ac/09/slides/2009-4412s1-01-FDA.pdf (Accessed 7 November 2010). 
Patel V, Lin FJ, Ojo O, Rao S, Yu S, Zhan L, Touchette DR. Cost-utility analysis of genotype-guided antiplatelet therapy in patients with moderate-to-high risk acute coronary syndrome and planned percutaneous coronary intervention. Pharmacy Practice 2014 Jul-Sep;12(3):438.

23. Memtsoudis SG, Besculides MC, Gaber L, Liu S, Gonzalez Della Valle A. Risk factors for pulmonary embolism after hip and knee arthroplasty: a population-based study. International orthopaedics. 2009;33(6):1739-1745. doi: 10.1007/s00264-008-0659-z

24. Desta Z, Zhao X, Shin JG, Flockhart DA. Clinical significance of the cytochrome P450 2C19 genetic polymorphism. Clin Pharmacokinet. 2002;41(12):913-958.

25. Eli Lilly and Company. A comparison of prasugrel (CS-747) and clopidogrel in acute coronary syndrome subjects who are to undergo percutaneous coronary intervention [ClinicalTrials.gov Identifier: NCT00097591] Bethesda, MD: Eli Lilly and Company; 2010. Available from: http://clinicaltrials.gov/ct2/show/results/NCT00097591?term=NCT00097591\&rank=1 (Accessed 8 October 2012).

26. Consumer Price Index (CPI): Bureau of Labor Statistics; 2011. Available from: www.bls.gov/cpi/ (Accessed 20 March 2012).

27. Red Book Online [Internet database, accessed through Micromedex 2.0]. Ann Arbor, MI: Truven Health Analytics; 2014

28. Kadkol S. Personal communication (estimated UIC laboratory costs for genetic testing). 2012.

29. Physician fee schedule (PFS) relative value files Baltimore, MD: Center for Medicare \& Medicaid Services; 2011. Available from: http://www.cms.gov/Medicare/Medicare-Fee-for-Service-Payment/PhysicianFeeSched/PFS-RelativeValue-Files.html (Accessed 13 March 2012).

30. Etemad LR, McCollam PL. Total first-year costs of acute coronary syndrome in a managed care setting. J Manag Care Pharm. 2005;11(4):300-306.

31. Beck JR, Pauker SG, Gottlieb JE, Klein K, Kassirer JP. A convenient approximation of life expectancy (the "DEALE"). II. Use in medical decision-making. Am J Med. 1982;73(6):889-897.

32. Fryback DG, Dunham NC, Palta M, Hanmer J, Buechner J, Cherepanov D, Herrington SA, Hays RD, Kaplan RM, Ganiats TG, Feeny D, Kind P. US norms for six generic health-related quality-of-life indexes from the National Health Measurement study. Med Care. 2007;45(12):1162-1170. doi: 10.1097/MLR.0b013e31814848f1

33. Christensen MC, Mayer S, Ferran JM. Quality of life after intracerebral hemorrhage: results of the Factor Seven for Acute Hemorrhagic Stroke (FAST) trial. Stroke. 2009;40(5):1677-1682. doi: 10.1161/strokeaha.108.538967

34. Nyman JA, Barleen NA, Dowd BE, Russell DW, Coons SJ, Sullivan PW. Quality-of-life weights for the US population: self-reported health status and priority health conditions, by demographic characteristics. Med Care. 2007;45(7):618628. doi: 10.1097/MLR.0b013e31803dce05

35. Tengs TO, Lin TH. A meta-analysis of quality-of-life estimates for stroke. PharmacoEconomics. 2003;21(3):191-200

36. Healthcare Cost and Utilization Project (HCUP). Agency for Healthcare Research and Quality, Rockville, MD: HCUPnet; 2008. Available from: http://hcupnet.ahrq.gov/ (Accessed 10 May 2011).

37. Guzauskas GF, Hughes DA, Bradley SM, Veenstra DL. A risk-benefit assessment of prasugrel, clopidogrel, and genotype-guided therapy in patients undergoing percutaneous coronary intervention. Clin Pharmacol Ther. 2012;91(5):829-837.

38. Mauskopf JA, Graham JB, Bae JP, Ramaswamy K, Zagar AJ, Magnuson EA, Cohen DJ, Meadows ES. Costeffectiveness of prasugrel in a US managed care population. J Med Econ. 2012;15(1):166-174. doi: 10.3111/13696998.2011.637590

39. Holmes MV, Perel P, Shah T, Hingorani AD, Casas JP. CYP2C19 genotype, clopidogrel metabolism, platelet function, and cardiovascular events: a systematic review and meta-analysis. JAMA. 2011;306(24):2704-2714. doi: 10.1001/jama.2011.1880

40. Cattaneo M, Podda GM. State of the art of new P2Y12 antagonists. Intern Emerg Med. 2010;5(5):385-391. doi: $10.1007 / \mathrm{s} 11739-010-0363-z$

41. Wiviott SD, Desai N, Murphy SA, Musumeci G, Ragosta M, Antman EM, Braunwald E. Efficacy and safety of intensive antiplatelet therapy with prasugrel from TRITON-TIMI 38 in a core clinical cohort defined by worldwide regulatory agencies. Am J Cardiol. 2011;108(7):905-911. doi: S0002-9149(11)01906-0

42. Morrow DA, Wiviott SD, White HD, Nicolau JC, Bramucci E, Murphy SA, Bonaca MP, Ruff CT, Scirica BM, McCabe CH, Antman EM, Braunwald E. Effect of the novel thienopyridine prasugrel compared with clopidogrel on spontaneous and procedural myocardial infarction in the Trial to Assess Improvement in Therapeutic Outcomes by Optimizing Platelet Inhibition with Prasugrel-Thrombolysis in Myocardial Infarction 38: an application of the classification system from the universal definition of myocardial infarction. Circulation. 2009;119(21):2758-2764. doi: CIRCULATIONAHA.108.833665

43. Eisenberg MJ, Filion KB, Azoulay A, Brox AC, Haider S, Pilote L. Outcomes and cost of coronary artery bypass graft surgery in the United States and Canada. Arch Intern Med. 2005;165(13):1506-1513.

44. Nagle PC, Smith AW. Review of recent US cost estimates of revascularization. Am J Manag Care. 2004 Oct;10(11 Suppl):S370-S376

45. O'Brien JA, Patrick AR, Caro J. Estimates of direct medical costs for microvascular and macrovascular complications resulting from type 2 diabetes mellitus in the United States in 2000. Clin Ther. 2003;25(3):1017-1038. doi: S0149291803801224

46. Sculpher MJ, Lozano-Ortega G, Sambrook J, Palmer S, Ormanidhi O, Bakhai A, Flather M, Steg PG, Mehta SR, Weintraub W. Fondaparinux versus Enoxaparin in non-ST-elevation acute coronary syndromes: short-term cost and long-term cost-effectiveness using data from the Fifth Organization to Assess Strategies in Acute Ischemic Syndromes Investigators (OASIS-5) trial. Am Heart J. 2009;157(5):845-52. doi: S0002-8703(09)00149-5

47. Agarwal S, Banerjee S, Tuzcu EM, Kapadia SR. Influence of age on revascularization related costs of hospitalization among patients of stable coronary artery disease. Am J Cardiol. 2010;105(11):1549-1554. doi: 10.1016/j.amjcard.2010.01.012

48. Reed SD, Blough DK, Meyer K, Jarvik JG. Inpatient costs, length of stay, and mortality for cerebrovascular events in community hospitals. Neurology. 2001;57(2):305-314. 
Patel V, Lin FJ, Ojo O, Rao S, Yu S, Zhan L, Touchette DR. Cost-utility analysis of genotype-guided antiplatelet therapy in patients with moderate-to-high risk acute coronary syndrome and planned percutaneous coronary intervention. Pharmacy Practice 2014 Jul-Sep;12(3):438.

49. Taylor TN, Davis PH, Torner JC, Holmes J, Meyer JW, Jacobson MF. Lifetime cost of stroke in the United States. Stroke. 1996;27(9):1459-1466.

50. Amin M, Fergusson D, Aziz A, Wilson K, Coyle D, Hebert P. The cost of allogeneic red blood cells--a systematic review. Transfus Med. 2003;13(5):275-285.

51. Jefferies LC, Sachais BS, Young DS. Blood transfusion costs by diagnosis-related groups in 60 university hospitals in 1995. Transfusion. 2001;41(4):522-529.

52. Resnic FS, Arora N, Matheny M, Reynolds MR. A cost-minimization analysis of the angio-seal vascular closure device following percutaneous coronary intervention. Am J Cardiol. 2007;99(6):766-770. doi: S0002-9149(06)02363-0

53. Smith TL, Melfi CA, Kesterson JA, Sandmann BJ, Kotsanos JG. Direct medical charges associated with myocardial infarction in patients with and without diabetes. Med Care. 1999;37(4 Suppl Lilly):AS4-AS11.

54. Eisenstein EL, Shaw LK, Anstrom KJ, Nelson CL, Hakim Z, Hasselblad V, Mark DB. Assessing the clinical and economic burden of coronary artery disease: 1986-1998. Med Care. 2001;39(8):824-835.

55. Arias E. United States life tables, 2006. Natl Vital Stat Rep. 2010;58(21):1-40. 